\title{
EPIDEMIOLOGY OF LIMB INJURIES IN PAEDIATRIC PATIENTS RECEIVING CARE FROM EMERGENCY MEDICAL SERVICE TEAMS: DESCRIPTIVE ANALYSYS
}

\author{
Kamil Safiejko ${ }^{1}$, Marek Malysz ${ }^{2} \oplus$, Lukasz Szarpak $^{2} \odot$, Jerzy Robert Ladny ${ }^{1} \oplus$ \\ 'Department of General and Endocrinological Surgery, Medical University of Bialystok, Poland \\ ${ }^{2}$ Lazarski University, Medical Faculty, Warsaw, Poland
}

\begin{abstract}
INTRODUCTION: Injury-related interventions currently place a heavy workload on emergency medical teams in both adults and paediatric patients. One of the most common types of injuries are limb injuries caused by physical activity, falls or traffic accidents. It is extremely important to provide adequate protection for the paediatric patient in case of injury, as homeostasis disorders can occur very quickly in this age group.

The aim of the study was to obtain data on the type and frequency of limb injuries in the group of paediatric patients who received medical rescue services interventions. An attempt was also made to specify the most frequent causes of limb injuries.
\end{abstract}

MATERIAL AND METHODS: The study was based on a retrospective analysis of medical records of emergency rescue teams in the period from November 2017 to October 2018. The study included an analysis of interventions to patients under 18 years of age to whom EMS teams intervened due to limb injury. The analysis included sociodemographic data such as age, gender, time and place of the injury, as well as the type of injury based on the ICD-10 classification.

RESULTS: In the studied period, 289 interventions in paediatric patients with limb injuries were recorded, which constituted $9.8 \%$ of all interventions in paediatric patients. The main site of the injury was a school. Upper limb injuries were reported in 123 cases, which constituted $42.6 \%$ of the intervention to the studied group of patients. The upper limb injuries were predominantly caused by forearm fractures $(n=33 ;$ Tab. 3$)$, while the lower limb - by knee joint injuries.

CONCLUSIONS: Limb injuries account for nearly $10 \%$ of all EMS interventions in paediatric patients. The main site of the injury was a school and the most frequent were upper limb injuries including forearm fractures, while for the lower limb - knee joint injuries. Further action should be taken to reduce the number of limb injuries in children.

KEY WORDS: limb; trauma; injury; prehospital care; emergency medicine service; emergency medicine

Disaster Emerg Med J 2019; 4(4): 151-157

\section{INTRODUCTION}

Injury-related interventions currently place a heavy workload on emergency medical teams in both adults and paediatric patients. Injuries to children are a very important reason for visiting emergency departments and hospitalization. Children's injuries have different causes and, depending on the severity and location of the injury and co-morbidities, maybe 
a significant cause of mortality and chronic health disability. Limb injuries occur in children in different age groups, and the age of children may influence the location of injuries and their characteristics [1]. The occurrence of injuries is influenced by many factors related to parental care, environmental exposure, sport and physical activity [2]. In some parts of the world, violence and ongoing military activities are an important factor in child injuries [3].

One of the most common types of injuries are limb injuries caused by physical activity, falls or traffic accidents. Injuries caused by sport practised by young people are of special importance [4] due to the different characteristics of the injuries, for example injury rates can be greater in collegiate versus high school baseball and in competition versus practice [5]. The number of injuries to children is evidenced by the fact that on average, a child is treated in a US emergency department for a nonfatal consumer productor sports and recreational activity-related injury every 6 seconds [6]. One of the causes of limb fractures in children can be abuse - especially common among infants [7]. Also, mistakes committed by parents and guardians of children can cause a problem [8]. It is extremely important to provide adequate protection for the paediatric patient in case of injury, as homeostasis disorders can occur very quickly in this age group. There are large differences in the mechanisms of injury, injury response, clinical signs and results of image examinations in adults and children. Injuries in children, especially in extreme age groups, require indepth clinical evaluation and specialist consultation. In many countries, the cost of treating injuries in children and, above all, the cost of further treatment and rehabilitation are being raised [8].

The aim of the study was to obtain data on the type and frequency of limb injuries in the group of paediatric patients who received medical rescue services interventions. An attempt to specify the most frequent causes of limb injuries was also made.

\section{MATERIAL AND METHODS}

The study was designed as a retrospective study of medical records of medical rescue teams from Piaseczno, Grodzisk Mazowiecki and Pruszków districts. The study protocol was approved by the Institutional Review Board of the Polish Society for Disaster Medicine (Approval number: 32.02.2018.IRB).

We analysed paediatric patients transported by a countywide EMS system between November
2017 and October 2018. The EMS catchment area includes urban, suburban, and rural areas over approximately 1234 square kilometres containing officially a population of 437 thousand people. However, the official population statistics are understated as the survey areas are a kind of accommodation for Warsaw. Thus, the real population may exceed one million people.

Special attention has been paid to the main socio-demographic features such as age, gender, location of the injury and other circumstances of the injury such as time and place of occurrence. All diseases are classified according to the International Statistical Classification of Diseases and Related Health Problems, Revision X (ICD-10).

The material was subjected to basic statistical analysis with the use of Statistica 13.3EN and MS Office Excel 2010, calculating basic descriptive statistics. For statistical comparisons, we used Fisher's exact test for qualitative variables and Student's test for quantitative variables. Values of $P \leq 0.05$ were considered significant.

\section{Population characteristics \\ RESULTS}

In the period under study, medical rescue teams performed 42482 interventions, of which 2942 were performed in patients under 18 years of age. Of all the interventions performed in paediatric patients, $9.8 \%(n=289)$ were interventions for limb injuries.

The majority of the patients were males, accounting for $59.9 \%$ of the studied group. The mean age of the study group was $11.4 \pm 3.9$ years and was slightly higher for boys than girls $(11.4 \pm 3.9$ vs. $11.3 \pm 3.8$ years, respectively; $p=0.809$; Fig. 1 ).

The main place of injuries in the study group was a school, then a public place, a house and finally traffic. The detailed characteristics of the study group are presented in Table 1. In the case of injuries at home, they concerned the youngest patients (Fig. 2). The median age of boys and girls was $9.3 \pm 4.8$ vs. $9.3 \pm 5.3$ years. In the case of public place injuries, the most common among boys was at the age of $12.4 \pm 3.7$ years, and in the case of girls $-11.1 \pm 3.6$ years. The age of road traffic injuries was equal for girls and boys $(13.1 \pm 3.5$ vs. $11.5 \pm 3.9$ years, respectively), and for school injuries, the median age of injured girls was $12.0 \pm 2.7$ years and for boys $12.2 \pm 3.0$ years. 


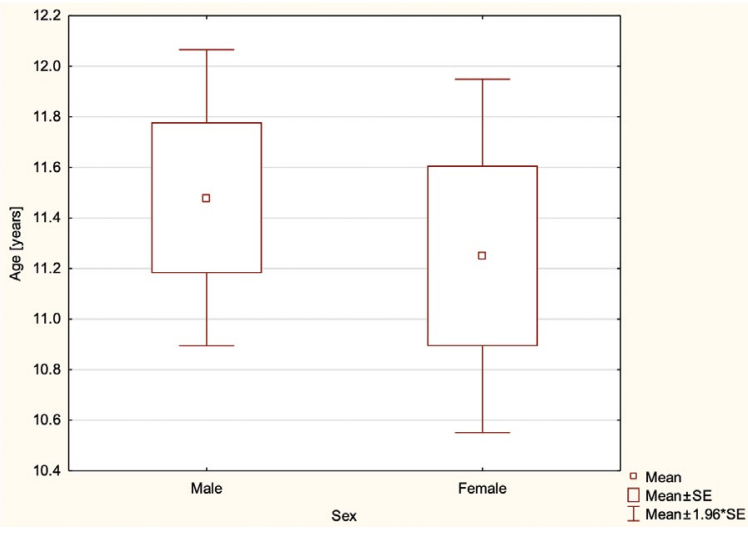

FIGURE 1. Mean age of study participants

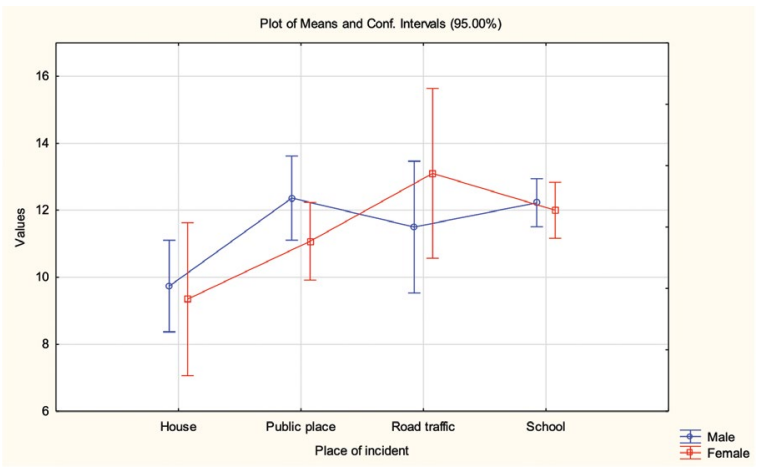

FIGURE 2. The main place of injuries in the study group compared with participants sex and age

\begin{tabular}{|c|c|c|c|c|c|c|c|}
\hline \multirow{2}{*}{ Parameter } & \multicolumn{2}{|c|}{ Total } & \multicolumn{2}{|c|}{ Female } & \multicolumn{2}{|c|}{ Male } & \multirow[t]{2}{*}{$\mathrm{p}$-value } \\
\hline & Count & Percent & Count & Percent & Count & Percent & \\
\hline No. of Patients & 289 & $100 \%$ & 116 & $40.1 \%$ & 173 & $59.9 \%$ & 0.812 \\
\hline \multicolumn{8}{|c|}{ Age group } \\
\hline$<4$ & 20 & $6.9 \%$ & 6 & $5.2 \%$ & 14 & $8.1 \%$ & \multirow{5}{*}{0.955} \\
\hline $4-7$ & 25 & $8.6 \%$ & 13 & $11.2 \%$ & 12 & $6.9 \%$ & \\
\hline $8-12$ & 120 & $41.5 \%$ & 47 & $40.5 \%$ & 73 & $42.2 \%$ & \\
\hline $13-15$ & 56 & $19.4 \%$ & 36 & $31.0 \%$ & 50 & $28.9 \%$ & \\
\hline 16-18 & 38 & $23.6 \%$ & 14 & $12.1 \%$ & 24 & $13.9 \%$ & \\
\hline \multicolumn{8}{|c|}{ Place of injury } \\
\hline Home & 72 & $24.9 \%$ & 23 & $19.8 \%$ & 49 & $28.3 \%$ & \multirow{4}{*}{0.388} \\
\hline School & 115 & $39.8 \%$ & 43 & $37.1 \%$ & 72 & $41.6 \%$ & \\
\hline Public place & 76 & $26.3 \%$ & 40 & $34.5 \%$ & 36 & $20.8 \%$ & \\
\hline Road traffic & 26 & $9.0 \%$ & 10 & $8.6 \%$ & 16 & $9.3 \%$ & \\
\hline
\end{tabular}

\section{Characteristics of injuries}

Upper limb injuries were reported in 123 cases, which constituted $42.6 \%$ of the intervention to the examined group of patients. Upper limb injuries were dominated by forearm fractures $(n=33 ;$ Tab. 2$)$ and lower limb injuries by knee joint injuries (Tab. 3). No statistically significant influence of gender on the type of injury was observed. The relationship between the age of sex and the type of injury is shown in Figure 3.

\section{The time frame of the injury}

Most injuries occurred in the afternoon between 12:00 and 18:00. $45.3 \%$ of all injuries analysed in the study group occurred in the afternoon (Tab. 4).

A detailed weekly distribution of injuries is shown in Table 4. The most frequent injuries occurred on Thursday and Friday. There were no significant differ- ences in the incidence of injuries between girls and boys in relation to the day of the injury $(p=0.910)$, month $(p=0.472)$ or season $(p=0.192)$.

\section{DISCUSSION}

The study analysed the documentation of medical records of emergency medical rescue teams that intervened in paediatric patients due to injuries to upper and lower extremities. In our study, 9.8\% of all the interventions performed in paediatric patients were interventions for limb injuries. This implies that emergency medical teams must be prepared to provide assistance in such cases. Given the number of interventions in children, limb injuries are a heavy burden for both emergency departments and paediatric surgery departments [9]. 


\begin{tabular}{|c|c|c|c|c|c|c|c|}
\hline \multirow{2}{*}{ Parameter } & \multicolumn{2}{|c|}{ Total } & \multicolumn{2}{|c|}{ Female } & \multicolumn{2}{|c|}{ Male } & \multirow[t]{2}{*}{$\mathrm{p}$-value } \\
\hline & Count & Percent & Count & Percent & Count & Percent & \\
\hline \multicolumn{8}{|c|}{ Shoulder and upper arm injuries } \\
\hline $\begin{array}{l}\text { S40 Superficial injury of } \\
\text { shoulder and upper arm }\end{array}$ & 5 & $1.7 \%$ & 3 & $2.6 \%$ & 2 & $1.2 \%$ & \multirow{6}{*}{0.425} \\
\hline $\begin{array}{l}\text { S41 Open wound of shoulder } \\
\text { and upper arm }\end{array}$ & 2 & $0.7 \%$ & - & - & 2 & $1.2 \%$ & \\
\hline $\begin{array}{l}\text { S42 Fracture of shoulder and } \\
\text { upper arm }\end{array}$ & 4 & $1.4 \%$ & 1 & $0.9 \%$ & 3 & $1.7 \%$ & \\
\hline $\begin{array}{l}\text { S43 Dislocation, sprain and } \\
\text { strain of joints and ligaments of } \\
\text { the shoulder girdle }\end{array}$ & 4 & $1.4 \%$ & - & - & 4 & $2.3 \%$ & \\
\hline $\begin{array}{l}\text { S49 Other and unspecified } \\
\text { injuries of shoulder and upper } \\
\text { arm }\end{array}$ & 12 & $4.2 \%$ & 3 & $2.6 \%$ & 9 & $5.2 \%$ & \\
\hline Total & 27 & $9.3 \%$ & 7 & $6.0 \%$ & 20 & $31.6 \%$ & \\
\hline \multicolumn{8}{|c|}{ Forearm injuries } \\
\hline $\begin{array}{l}\text { S50 Superficial injury of } \\
\text { forearm }\end{array}$ & 8 & $2.8 \%$ & 3 & $2.6 \%$ & 5 & $2.9 \%$ & \multirow{6}{*}{0.117} \\
\hline S51 Open wound of forearm & 10 & $3.5 \%$ & 5 & $4.3 \%$ & 5 & $2.9 \%$ & \\
\hline S52 Fracture of forearm & 33 & $11.4 \%$ & 14 & $12.1 \%$ & 29 & $17.8 \%$ & \\
\hline $\begin{array}{l}\text { S53 Dislocation, sprain and } \\
\text { strain of joints and ligaments } \\
\text { of elbow }\end{array}$ & 4 & $1.4 \%$ & - & - & 4 & $2.3 \%$ & \\
\hline $\begin{array}{l}\text { S59 Other and unspecified } \\
\text { injuries of the forearm }\end{array}$ & 14 & $4.8 \%$ & 4 & $3.4 \%$ & 10 & $5.8 \%$ & \\
\hline Total & 69 & $23.9 \%$ & 26 & $22.4 \%$ & 53 & $30.6 \%$ & \\
\hline \multicolumn{8}{|c|}{ Wrist and hand injuries } \\
\hline $\begin{array}{l}\text { S60 Superficial injury of wrist } \\
\text { and hand }\end{array}$ & 11 & $3.8 \%$ & 6 & $5.2 \%$ & 5 & $2.9 \%$ & \multirow{7}{*}{0.207} \\
\hline $\begin{array}{l}\text { S61 Open wounds of wrist and } \\
\text { hand }\end{array}$ & 1 & $0.3 \%$ & - & - & 1 & $0.6 \%$ & \\
\hline $\begin{array}{l}\text { S62 Fracture at wrist and hand } \\
\text { level }\end{array}$ & 5 & $1.7 \%$ & 3 & $2.6 \%$ & 2 & $1.2 \%$ & \\
\hline $\begin{array}{l}\text { S67 Crushing injury of wrist } \\
\text { and hand }\end{array}$ & 2 & $0.7 \%$ & - & - & 2 & $1.2 \%$ & \\
\hline $\begin{array}{l}\text { S68 Traumatic amputation of } \\
\text { thumb wrist and hand }\end{array}$ & 2 & $0.7 \%$ & 1 & $0.9 \%$ & 1 & $0.6 \%$ & \\
\hline $\begin{array}{l}\text { S69 Other and unspecified } \\
\text { injury of wrist and hand }\end{array}$ & 6 & $2.1 \%$ & - & - & 6 & $3.5 \%$ & \\
\hline Total & 27 & $9.3 \%$ & 10 & $8.6 \%$ & 27 & $15.6 \%$ & \\
\hline
\end{tabular}

In our study group, the majority of the patients with limb injuries were males, accounting for 59.9\% of the studied group. This is related to the higher physical activity of boys and is consistent with the results of other studies including studies on adolescent lifestyle patterns [10]. Issin et al. analysed paediatric fractures in the metropolitan area of Turkey [11]. They similarly showed that $65 \%$ of the paediatric patients with fractures were males and $35 \%$ were females.

Our study revealed that the mean age of paediatric patients with limb injuries was equal for boys and girls (11.4 \pm 3.9 vs. $11.3 \pm 3.8$ years, respectively) however, at this age the physical activity of girls and boys may be at a similar level. 


\begin{tabular}{|c|c|c|c|c|c|c|c|}
\hline \multirow{2}{*}{ Parameter } & \multicolumn{2}{|c|}{ Total } & \multicolumn{2}{|c|}{ Female } & \multicolumn{2}{|c|}{ Male } & \multirow[t]{2}{*}{$p$-value } \\
\hline & Count & Percent & Count & Percent & Count & Percent & \\
\hline \multicolumn{8}{|c|}{ Hip and thigh injuries } \\
\hline $\begin{array}{l}\text { S70 Superficial injury of hip and } \\
\text { thigh }\end{array}$ & 11 & $3.8 \%$ & 5 & $4.3 \%$ & 6 & $3.5 \%$ & \multirow{7}{*}{0.774} \\
\hline $\begin{array}{l}\text { S71 Open wound of hip and } \\
\text { thigh }\end{array}$ & 4 & $1.4 \%$ & 2 & $1.7 \%$ & 2 & $1.2 \%$ & \\
\hline S72 Fracture of femur & 2 & $0.7 \%$ & 1 & $0.9 \%$ & 1 & $0.6 \%$ & \\
\hline $\begin{array}{l}\text { S73 Dislocation, sprain and } \\
\text { strain of joint and ligaments } \\
\text { of hip }\end{array}$ & 1 & $0.3 \%$ & - & - & 1 & $0.6 \%$ & \\
\hline $\begin{array}{l}\text { S76 Injury of muscle and } \\
\text { tendon at hip and thigh level }\end{array}$ & 1 & $0.3 \%$ & 1 & $0.9 \%$ & - & - & \\
\hline $\begin{array}{l}\text { S79 Other and unspecified } \\
\text { injuries of hip and thigh }\end{array}$ & 5 & $1.7 \%$ & - & - & 5 & $2.9 \%$ & \\
\hline Total & 24 & $8.3 \%$ & 9 & $7.8 \%$ & 15 & $8.7 \%$ & \\
\hline \multicolumn{8}{|c|}{ Lower leg injuries } \\
\hline S80 Superficial injury of lower leg & 8 & $2.8 \%$ & 6 & $5.2 \%$ & 2 & $1.2 \%$ & \multirow{6}{*}{0.351} \\
\hline S81 Open wound of lower leg & 15 & $5.2 \%$ & 2 & $1.7 \%$ & 13 & $7.5 \%$ & \\
\hline $\begin{array}{l}\text { S82 Fracture of lower leg, } \\
\text { including ankle }\end{array}$ & 5 & $1.7 \%$ & - & - & 5 & $2.9 \%$ & \\
\hline $\begin{array}{l}\text { S83 Dislocation, sprain and } \\
\text { strain of joints and ligaments of } \\
\text { the knee }\end{array}$ & 30 & $10.4 \%$ & 15 & $12.9 \%$ & 15 & $8.7 \%$ & \\
\hline $\begin{array}{l}\text { S89 Other and unspecified } \\
\text { injuries of the lower leg }\end{array}$ & 18 & $6.2 \%$ & 6 & $5.2 \%$ & 12 & $6.9 \%$ & \\
\hline Total & 76 & $26.3 \%$ & 29 & $25.0 \%$ & 47 & $27.2 \%$ & \\
\hline \multicolumn{8}{|c|}{ Ankle joint and foot injuries } \\
\hline $\begin{array}{l}\text { S90 Superficial injury of ankle } \\
\text { and foot }\end{array}$ & 11 & $3.8 \%$ & 4 & $3.4 \%$ & 7 & $4.0 \%$ & \multirow{5}{*}{0.097} \\
\hline $\begin{array}{l}\text { S93 Dislocation, sprain and } \\
\text { strain of joints and ligaments at } \\
\text { ankle and foot level }\end{array}$ & 14 & $4.8 \%$ & 7 & $6.0 \%$ & 7 & $4.0 \%$ & \\
\hline $\begin{array}{l}\text { S96 Injury of muscle and } \\
\text { tendon at ankle and foot level }\end{array}$ & 6 & $2.1 \%$ & - & - & 6 & $3.5 \%$ & \\
\hline $\begin{array}{l}\text { S99 Other and unspecified } \\
\text { injuries of ankle and foot }\end{array}$ & 35 & $12.1 \%$ & 16 & $13.8 \%$ & 19 & $11.0 \%$ & \\
\hline Total & 66 & $22.8 \%$ & 27 & $23.3 \%$ & 39 & $22.5 \%$ & \\
\hline
\end{tabular}

In our study the main place of injuries in the study group was a school, then a public place, a house and finally traffic. a school is a place where the child spends a considerable amount of time. School not only provides physical education but also encourages kids to spontaneously play team games and engage in physical activities [12]. The available results indicate a wide variety of trauma locations in children and their relationship to the type of injury.
Upper limb injuries were reported in $42.6 \%$ of the intervention to the examined group of patients. Upper limb injuries were dominated by forearm fractures and lower limb injuries by knee joint injuries. Available studies have shown that the location of injuries depends on the mechanism of its occurrence, particularly in road traffic accident victims [13].

In our study, most injuries occurred in the afternoon between 12:00 and 18:00 it is most sim- 


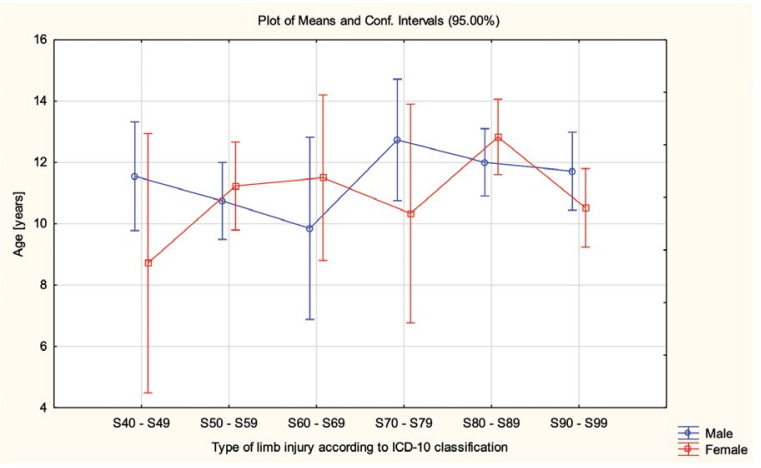

FIGURE 3. The type of injuries in the study group comparing with participants sex and age ilarly related to children taking up physical activity immediately after school, during a long break and on their way home from school and in the afternoon before sunset. $45.3 \%$ of all injuries analysed in the study group occurred in the afternoon and the most frequent injuries occurred on Thursday and Friday, however, there were no significant differences in the incidence of injuries between girls and boys in relation to the day of the injury, month or season. The final days of the week are a period of reducing the burden on children to prepare for the next day's school day, which translates into higher levels of

\begin{tabular}{|c|c|c|c|c|c|c|c|}
\hline \multirow{2}{*}{ Parameter } & \multicolumn{2}{|c|}{ Total } & \multicolumn{2}{|c|}{ Female } & \multicolumn{2}{|c|}{ Male } & \multirow{2}{*}{$\mathrm{p}$-value } \\
\hline & Count & Percent & Count & Percent & Count & Percent & \\
\hline \multicolumn{8}{|c|}{ Time of day } \\
\hline 00:01 - 06:00 & 2 & $0.7 \%$ & - & - & 2 & $1.2 \%$ & \multirow{4}{*}{0.793} \\
\hline $06: 01-12: 00$ & 91 & $31.5 \%$ & 34 & $29.3 \%$ & 57 & $32.9 \%$ & \\
\hline $12: 01-18: 00$ & 131 & $45.3 \%$ & 55 & $47.4 \%$ & 76 & $43.9 \%$ & \\
\hline $18: 01-24: 00$ & 65 & $22 . \%$ & 27 & $23.3 \%$ & 38 & $22.0 \%$ & \\
\hline \multicolumn{8}{|c|}{ Day of week } \\
\hline Monday & 38 & $13.1 \%$ & 21 & $18.1 \%$ & 17 & $9.8 \%$ & \multirow{7}{*}{0.910} \\
\hline Tuesday & 43 & $14.9 \%$ & 16 & $13.8 \%$ & 27 & $15.6 \%$ & \\
\hline Wednesday & 48 & $16.6 \%$ & 13 & $11.2 \%$ & 35 & $20.2 \%$ & \\
\hline Thursday & 54 & $18.7 \%$ & 23 & $19.8 \%$ & 31 & $17.9 \%$ & \\
\hline Friday & 50 & $17.3 \%$ & 16 & $13.8 \%$ & 34 & $19.6 \%$ & \\
\hline Saturday & 27 & $9.3 \%$ & 12 & $10.3 \%$ & 15 & $8.7 \%$ & \\
\hline Sunday & 29 & $10.0 \%$ & 15 & $12.9 \%$ & 14 & $8.1 \%$ & \\
\hline \multicolumn{8}{|c|}{ Month } \\
\hline January & 19 & $6.6 \%$ & 5 & $4.3 \%$ & 14 & $8.1 \%$ & \multirow{12}{*}{0.472} \\
\hline February & 13 & $4.5 \%$ & 3 & $2.6 \%$ & 10 & $5.8 \%$ & \\
\hline March & 29 & $10.0 \%$ & 13 & $11.2 \%$ & 16 & $9.2 \%$ & \\
\hline April & 16 & $5.5 \%$ & 10 & $8.6 \%$ & 6 & $3.5 \%$ & \\
\hline May & 43 & $14.9 \%$ & 17 & $14.6 \%$ & 26 & $15.0 \%$ & \\
\hline June & 37 & $12.8 \%$ & 18 & $15.5 \%$ & 19 & $10.9 \%$ & \\
\hline July & 21 & $7.3 \%$ & 6 & $5.2 \%$ & 15 & $8.7 \%$ & \\
\hline August & 20 & $6.9 \%$ & 8 & $6.9 \%$ & 12 & $6.9 \%$ & \\
\hline September & 15 & $5.2 \%$ & 4 & $3.4 \%$ & 11 & $6.4 \%$ & \\
\hline October & 27 & $9.3 \%$ & 11 & $9.5 \%$ & 16 & $9.2 \%$ & \\
\hline November & 21 & $7.3 \%$ & 11 & $9.5 \%$ & 10 & $5.8 \%$ & \\
\hline December & 28 & $9.7 \%$ & 10 & $8.6 \%$ & 18 & $10.4 \%$ & \\
\hline \multicolumn{8}{|c|}{ Season } \\
\hline Spring & 88 & $30.4 \%$ & 40 & $34.5 \%$ & 48 & $27.7 \%$ & \multirow{4}{*}{0.192} \\
\hline Summer & 78 & $26.9 \%$ & 32 & $27.6 \%$ & 43 & $24.9 \%$ & \\
\hline Autumn & 63 & $21.8 \%$ & 26 & $22.4 \%$ & 37 & $21.4 \%$ & \\
\hline Winter & 60 & $20.9 \%$ & 18 & $15.5 \%$ & 42 & $26.0 \%$ & \\
\hline
\end{tabular}


physical activity. Issin et al. in their analysis paediatric fractures in a metropolitan area of Turkey [11] have shown that fractures in paediatric patients had some seasonal, daily, and circadian variations, similarly as Odetola et al. [9]. This study has its strengths and weaknesses. Among the strengths is the large analysed group. The basic weakness is the retrospective nature of the analysis.

\section{Conclusions}

Limb injuries account for nearly $10 \%$ of all EMS interventions in paediatric patients. The main site of the injury was a school and the most frequent were upper limb injuries including forearm fractures, while for the lower limb - knee joint injuries. Further action should be taken to reduce the number of limb injuries in children.

\section{REFERENCES}

1. Barnard AM, Nelson NG, Xiang $H$, et al. Pediatric mobility aid-related injuries treated in US emergency departments from 1991 to 2008. Pediatrics. 2010; 125(6): 1200-1207, doi: 10.1542/peds.2009-3286, indexed in Pubmed: 20498179.

2. Chéron C, Le Scanff C, Leboeuf-Yde C. Association between sports type and overuse injuries of extremities in children and adolescents: a systematic review. Chiropr Man Therap. 2016; 24: 41, doi: 10.1186/ s12998-016-0122-y, indexed in Pubmed: 27872744.

3. Er E, Çorbacıoğlu ŞK, Güler $S$, et al. Analyses of demographical and injury characteristics of adult and pediatric patients injured in Syrian civil war. Am J Emerg Med. 2017; 35(1): 82-86, doi: 10.1016/j. ajem.2016.10.008, indexed in Pubmed: 27771222.

4. Montgomery C, Porter A, Parks C, et al. Football-Related Pediatric Extremity Fractures and Dislocations: Size Matters. Orthopedics. 2018; 41(4): 216-221, doi: 10.3928/01477447-20180628-03, indexed in Pubmed: 30035799.
5. Wasserman EB, Sauers EL, Register-Mihalik JK, et al. The First Decade of Web-Based Sports Injury Surveillance: Descriptive Epidemiology of Injuries in US High School Boys' Baseball (2005-2006 Through 20132014) and National Collegiate Athletic Association Men's Baseball (2004-2005 Through 2013-2014). J Athl Train. 2019; 54(2): 198-211, doi: 10.4085/1062-6050-239-17, indexed in Pubmed: 30951387.

6. Kamboj AK, Chounthirath T, Hodges NL, et al. Nonfatal Pediatric Injuries Associated With Consumer Products and Sports and Recreational Activities in the United States. Pediatr Emerg Care. 2019 [Epub ahead of print], doi: 10.1097/PEC.0000000000001778, indexed in Pubmed: 30829840.

7. Berthold O, Frericks B, John T, et al. Abuse as a Cause of Childhood Fractures. Dtsch Arztebl Int. 2018; 115(46): 769-775, doi: 10.3238/ arztebl.2018.0769, indexed in Pubmed: 30602409.

8. Wegmann $\mathrm{H}$, Orendi I, Singer $\mathrm{G}$, et al. The epidemiology of fractures in infants -Which accidents are preventable? Injury. 2016; 47(1): 188-191, doi: 10.1016/j.injury.2015.08.037, indexed in Pubmed: 26384660.

9. Odetola FO, Gebremariam A. Paediatric trauma in the USA: patterns of emergency department visits and associated hospital resource use. Int J Inj Contr Saf Promot. 2015; 22(3): 260-266, doi: 10.1080/17457300.2014.925937, indexed in Pubmed: 24941303.

10. Agostinis-Sobrinho C, Gómez-Martínez $S$, Nova E, et al. Lifestyle patterns and endocrine, metabolic, and immunological biomarkers in European adolescents: The HELENA study. Pediatr Diabetes. 2019; 20(1): 23-31, doi: 10.1111/pedi.12802, indexed in Pubmed: 30471163.

11. Issin A, Kockara N, Oner A, et al. Epidemiologic Properties of Pediatric Fractures in a Metropolitan Area of Turkey. Medicine (Baltimore). 2015; 94(43): e1877, doi: 10.1097/MD.0000000000001877, indexed in Pubmed: 26512602.

12. Huleatt JB, Nissen CW, Milewski MD. Pediatric Sports Medicine Injuries: Common Problems and Solutions. Clin Sports Med. 2018; 37(2): 351362, doi: 10.1016/j.csm.2017.12.012, indexed in Pubmed: 29525032.

13. Rubin G, Peleg K, Givon A, et al. Israel Trauma Group. Upper extremity fractures among hospitalized pediatric road traffic accident victims. Am J Emerg Med. 2015; 33(5): 667-670, doi: 10.1016/j. ajem.2015.02.017, indexed in Pubmed: 25726065. 